Gut, 1972, 13, 421-426

\title{
Renal blood flow in malignant disease of the liver
}

\author{
M. C. KEW, CAROL A. LIMBRICK, R. R. VARMA, AND SHEILA SHERLOCK \\ From the Departments of Medicine and Medical Physics, Royal Free Hospital, London
}

SUMMARY Although functional renal failure has been reported in patients with malignant disease of the liver, renal haemodynamics and function have not been investigated. Renal and intrarenal blood flow was measured using the ${ }^{133}$ Xenon washout technique and creatinine clearances by the standard method in 14 patients with a variety of primary and secondary tumours of the liver in the absence of cirrhosis and without evidence of renal disease. In 11 patients renal and outer cortical blood flow was reduced and this was sometimes accompanied by a reduction in glomerular filtration rate. The pattern of renal circulatory changes was similar to that seen in renal dysfunction associated with hepatic cirrhosis. Possible causes of these disturbances and their significance in relation to the aetiology of functional renal failure in liver disease are discussed.

Vesin, Roberti, and Viguié in 1965 reported five patients with hepatic malignancy in whom oliguric renal failure developed without an obvious cause. They likened the syndrome to that seen in patients with advanced cirrhosis of the liver (Papper, Belsky, and Bleifer, 1959; Baldus, Feichter, and Summerskill, 1964a; Shear, Kleinerman, and Gabuzda, 1965). The cause and nature of the renal failure in the latter circumstance has not been determined, but the primary abnormality is thought to be reduced renal perfusion (Baldus, Feichter, Summerskill, Hunt, and Wakim, 1964b; Schroeder, Shear, Sancetta, and Gabuzda, 1967; Tristani and Cohn, 1967; Epstein, Berk, Hollenberg, Adams, Chalmers, Abrams, and Merrill, 1970) with a redistribution of intrarenal blood flow away from the cortex (Baldus, Summerskill, Hunt, and Maher, 1964c; Shear et al, 1965; Schroeder et al, 1967; Tristani and Cohn, 1967; Epstein et al, 1970; Kew, Brunt, Varma, Hourigan, Williams, and Sherlock, 1971a) and a fall in glomerular filtration rate (Baldus et al, 1964b; Shear et al, 1965). In two of the patients of Vesin et al primary cancer of the liver was associated with hepatic cirrhosis, and renal dysfunction may have been attributable to cirrhosis rather than the tumour. However, the other three had secondary carcinoma of the liver and no cirrhosis and in these patients at least some other mechanism must have been operative. We have measured renal and intrarenal blood flow and creatinine clearances in a group of patients with a variety of primary and secondary tumours of the liver who showed no evidence of primary renal

Received for publication 29 March 1972. disease and did not have cirrhosis, and have found renal circulatory disturbances similar to those described in cirrhosis. As both primary and secondary hepatic malignancy carries a grave prognosis, it may be argued that the appearance of progressive renal failure in these patients is of little practical importance. Nevertheless, the demonstration of renal haemodynamic and functional changes in this condition may serve to increase our understanding of the pathogenesis of functional renal failure and of the interrelationships between the liver and kidney.

\section{Material and Methods}

Fourteen patients with histologically proven malignant disease of the liver were investigated, one (no. 4) on two occasions. In four patients the tumour was of hepatic origin (primary hepatic cancer, intrahepatic bile duct cancer, malignant haemangioendothelioma, and hepatic Hodgkin's disease in one each) while the remainder had hepatic metastases from a primary focus elsewhere. In three instances the primary tumour was in the pancreas (adenocarcinoma in two and insulinoma in one), in one each the colon, rectum, parotid gland, small bowel (carcinoid tumour), and eye (melanoma), and in two it was unknown (the metastasis was an adenocarcinoma in both). In no patient was evidence of hepatic cirrhosis found on percutaneous biopsy, at laparotomy, or at necropsy. There were eight females and six males. Their ages ranged from 26 to 64 years with a mean of 46 . None of the patients gave a history of renal disease and all had a normal blood urea and serum creatinine concentration, urine 
analysis, intravenous pyelogram, and renal arteriogram at the time they were investigated. The kidneys were histologically normal in the two patients in whom necropsies were subsequently performed. The patients were receiving a full ward diet at the time they were investigated. All had a normal serum sodium concentration and urinary sodium excretion and none had ascites. No patient showed evidence of cardiovascular disease, and specifically the patient with the carcinoid tumour did not show the features of valvular heart disease. The patient with the insulin-producing tumour of the pancreas was not hypoglycaemic at the time of the investigation. Serum bilirubin, alkaline phosphatase, aspartate aminotransferase and albumin levels, and the prothrombin time (Thrombotest) were measured in each patient. Creatinine clearance was determined on the day before the renal haemodynamic studies; the standard method was used.

Renal haemodynamic studies were carried out at the time of coeliac axis or superior mesenteric arteriography done for diagnosis or to assess the extent of the tumour, or hepatic artery catheterization for intraarterial administration of cytotoxic drugs. The ${ }^{133}$ Xenon washout technique was used to measure renal and intrarenal blood flow. Details of the procedure and its implications were explained to the patients and their consent was obtained. The patients fasted for six to eight hours before the procedure and were premedicated with pethidine and diazepam. An end-hole polythene catheter with an inner diameter of $1.50 \mathrm{~mm}$ and an outer diameter of $2.70 \mathrm{~mm}$ was introduced into the femoral artery by the percutaneous route under local anaesthesia and passed, under fluoroscopic control, into the renal artery. The position of the catheter was checked by injecting a small volume of $45 \%$ sodium diatrizoate under fluoroscopic screening. This also served to verify that no contrast material (and hence ${ }^{133}$ Xenon) leaked out of the renal artery during or after the injection. A scintillation probe was aligned over the centre of the kidney at a height adjusted to just clear the anterior abdominal wall at the end of inspiration. The probe contained a $5 \mathrm{~cm}$ thallium-activated sodium iodide crystal located $7.5 \mathrm{~cm}$ from the end of a cylindrical collimator. The output from the probe was led through a pulse-height discriminator with a window setting of 50 to $110 \mathrm{KeV}$ to a ratemeter and thence to a chart recorder. The paper was run at $12 \mathrm{~cm}$ per minute with a time constant of 1 second. Background count rates were less than 30 counts per second while peak count rates after the injection were greater than 1500 counts per second. A bolus of 600 to $1000 \mu \mathrm{Ci}$ of ${ }^{133}$ Xenon dissolved in $0.8-1.0 \mathrm{ml}$ of sterile isotonic saline solution was injected as rapidly as possible through one arm of a two-way tap connected to the catheter. This was followed immediately by $5 \mathrm{ml}$ of sterile isotonic saline solution through the second arm to flush the ${ }^{133}$ Xenon solution out of the catheter. The syringes and two-way tap were removed from the immediate area of the detector but were then left in the same position throughout the recording to ensure a constant background activity.

Mean renal blood flow was calculated from the initial disappearance slope of the washout curve (Ingvar and Lassen, 1962). The intrarenal distribution of blood flow was determined by compartmental analysis, using the 'peeling-off' technique described by Zilversmit (1960), and with an analog computer. Because random error may be introduced in the translation of the washout curve from the recorder write-out to the semi-logarithmic replot and, more especially, in the visual estimation of the slope and hence half-time of the components (Newman and Skinner, 1969), we have preferred to use the results obtained with the analog computer. Three components can be accurately obtained from a 20-minute tracing (Ladefoged, 1966). The first (or most rapid) component represents clearance of the inert gas from the outer renal cortex, the second clearance from the juxtamedullary region and outer medulla, and the third from the inner medulla (Thorburn, Kopald, Herd, Hollenberg, O'Morchoe, and Barger, 1963; Ter-Pogossian, Koehler, and Potchen, 1968). To allow repeated studies some of the washout curves were continued for only six minutes. In these recordings the third component was represented by a horizontal line drawn through the log counts per second at five minutes. Thorburn et al (1963) and Rosen, Hollenberg, Dealy, and Merrill (1968) have shown that the slope of the first component can be accurately derived from such a recording. Flow rate was calculated from the slope (half time) of the component and the partition coefficient for renal parenchyma $(0.65$ corrected according to the patient's haematocrit (Andersen and Ladefoged, 1965) ) as described by Ladefoged (1966). The percentage distribution of blood flow to the three regions of the kidney was calculated from the zero-time intercept of each of the components (Dobson and Warner, 1957).

Only three patients with a normal liver and kidneys were available as controls. All had normal serum and urinary sodium levels and were receiving a full ward diet. The values for mean renal blood flow $(225 \pm 18 \mathrm{ml} / 100 \mathrm{~g} /$ minute; mean \pm SEM $)$ and first component blood flow $\left(C_{1}\right)(317 \pm 11.8$ $\mathrm{ml} / 100 \mathrm{~g} /$ minute) are lower than those found by Epstein et al (1970) using the same technique in 36 healthy individuals in whom renal arteriography was performed during assessment of their suitability as 
kidney donors $(338 \pm 7 \mathrm{ml} / 100 \mathrm{~g} /$ minute and $410 \pm$ $9 \mathrm{ml} / 100 \mathrm{~g} /$ minute respectively). The percentage distribution of blood flow to $C_{1}(71 \pm 3.6 \%)$ was similar to that found in the earlier study $(74 \pm 1 \%)$. Based on the findings in our three control subjects, we have taken the lower limits of normal for mean renal blood flow as $190 \mathrm{ml} / 100 \mathrm{~g} /$ minute, $C_{1} 300 \mathrm{ml} /$ $100 \mathrm{~g} /$ minute, and percentage distribution to $C_{1}$ as $60 \%$.

\section{Results}

The general characteristics, diagnosis, selected tests of liver function, and urinary sodium excretion in the 14 patients are summarized in Table I. The renal and outer cortical blood flow and creatinine clearances of the patients and controls are shown in Table II. Renal perfusion was normal in three patients (nos. 1-3) but in the remainder mean renal and outer cortical blood flow and the percentage distribution of blood flow to the outer cortex was reduced. Examples of a normal washout curve (from a control subject) and abnormal curves in patients with hepatic malignancy are shown in Figure 1. When the ${ }^{133}$ Xenon washout curve was so slow that the first component could not be dis-

\begin{tabular}{|c|c|c|c|c|c|c|c|c|c|c|}
\hline No. & Age & $\operatorname{Sex}$ & Diagnosis & $\begin{array}{l}\text { Bilirubin } \\
(m g \%)\end{array}$ & $\begin{array}{l}\text { Albumin } \\
(g \%)\end{array}$ & $\begin{array}{l}\text { Thrombotest } \\
(\%)\end{array}$ & $\begin{array}{l}\text { Aspartate } \\
\text { Transaminase } \\
\text { (units) }\end{array}$ & $\begin{array}{l}\text { Alkaline } \\
\text { Phosphatase } \\
\text { (units) }\end{array}$ & $\begin{array}{l}P C V \\
(\%)\end{array}$ & $\begin{array}{l}\text { Urinary Sodium } \\
\text { (m-equiv/24 hr) }\end{array}$ \\
\hline 2 & 44 & $\mathbf{M}$ & Metastases (melanoma) & 0.6 & $4 \cdot 2$ & 90 & 12 & 24 & 36 & 125 \\
\hline \multirow[t]{2}{*}{3} & 59 & $\mathbf{F}$ & Intrahepatic bile duct & & & & & & & \\
\hline & & & cancer & $19 \cdot 5$ & $5 \cdot 1$ & 100 & 58 & 102 & 33 & 97 \\
\hline 4 & 37 & $\mathbf{F}$ & Haemangioendothelioma & 1.6 & $3 \cdot 8$ & 100 & 13 & 10 & 41 & 63 \\
\hline 5 & 50 & $\mathbf{F}$ & Metastases (unknown) & 0.6 & $2 \cdot 6$ & 48 & 25 & 13 & 36 & 86 \\
\hline 6 & 60 & $\mathbf{F}$ & Metastases (carcinoid) & 0.9 & $2 \cdot 2$ & 60 & 14 & 23 & 42 & 73 \\
\hline 7 & 57 & $\mathbf{M}$ & Metastases (insulinoma) & 0.6 & $4 \cdot 5$ & 60 & 15 & 10 & 46 & 105 \\
\hline 8 & 63 & $\mathbf{M}$ & Metastases (colon) & 0.5 & $2 \cdot 6$ & 100 & 13 & 22 & 35 & 77 \\
\hline 9 & 29 & $\mathbf{F}$ & Metastases (rectum) & 1.8 & 1.8 & 28 & 16 & 44 & 34 & 97 \\
\hline 10 & 29 & $\mathbf{F}$ & Metastases (parotid) & 0.5 & $3 \cdot 7$ & 100 & 7 & 8 & 35 & 72 \\
\hline 11 & 26 & $\mathbf{M}$ & Hepatoma & $1 \cdot 3$ & $2 \cdot 4$ & 86 & 33 & 105 & 44 & 65 \\
\hline 12 & 64 & $\mathbf{M}$ & Metastases (pancreas) & 0.5 & $4 \cdot 4$ & 100 & 8 & 10 & 34 & 81 \\
\hline 13 & 46 & $\mathbf{F}$ & Hodgkin's & $1 \cdot 0$ & $5 \cdot 0$ & 100 & 28 & 42 & 44 & 69 \\
\hline
\end{tabular}

Table I The general characteristics, diagnosis, selected tests of liver function, and urinary sodium excretion in the 14 patients

${ }^{1}$ Site of primary tumour.

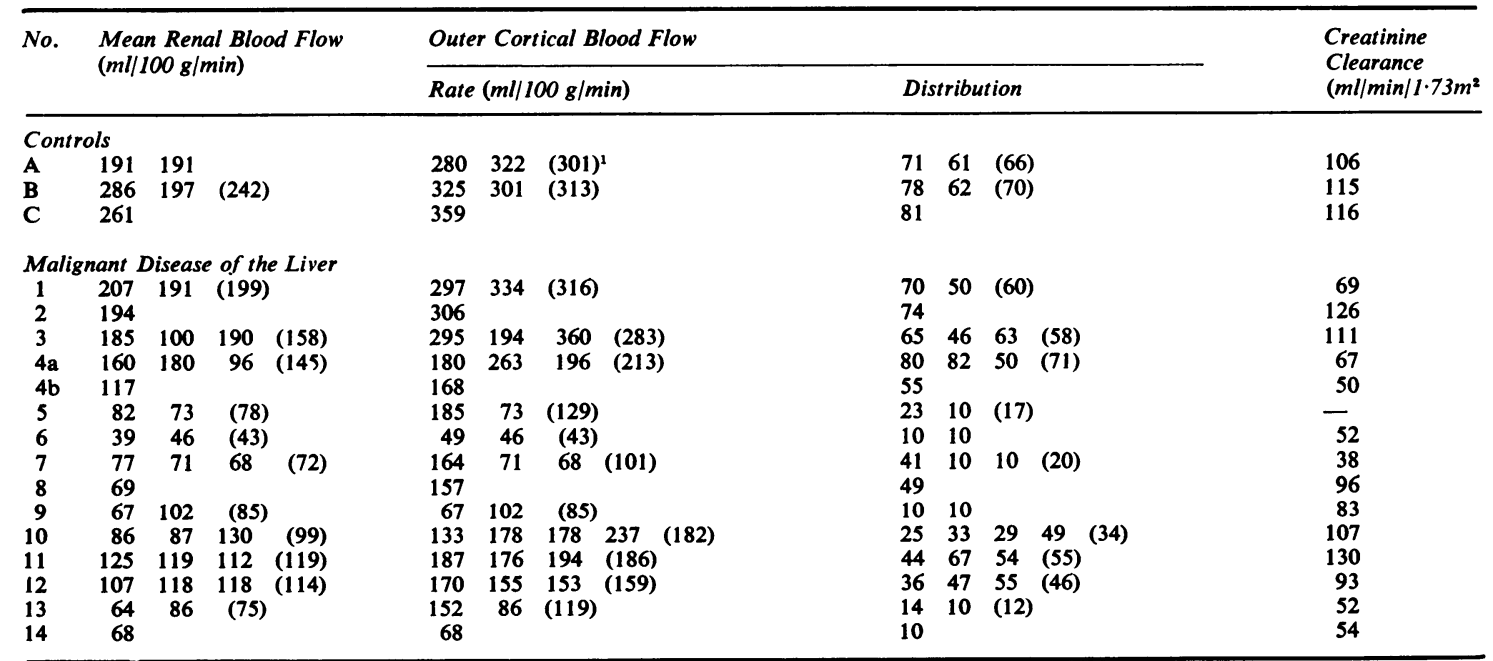

Table II Mean renal and outer cortical blood flow and creatinine clearances in the 14 patients with hepatic malignancy and in the control subjects

${ }^{1}$ Mean 
tinguished from the second (fusion curve), the percentage distribution of blood flow to the outer cortex was arbitrarily taken as $10 \%$. As these tracings appear to consist of only second and third components, the mean renal and juxtamedullary and outer medullary flow rates are the same if the former is calculated from the initial slope of the washout curve. In these circumstances the cortical flow was taken as being the same as the mean renal and second component flow rate. There was a good correlation between the percentage distribution of blood flow to the outer cortex and the flow rate through this region $(r=0.80, \quad P<0.001)$. The correlation between the percentage distribution to the cortex

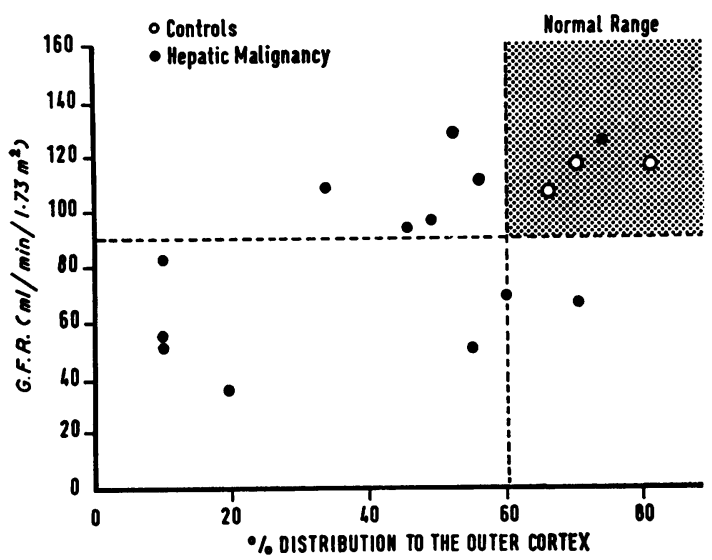

Fig. 2 Correlation between percentage distribution of blood flow to the outer renal cortex and creatinine clearance.
Fig. 1 Two examples of abnormal ${ }^{133}$ Xenon washout curves in patients with hepatic malignancy (nos. 12 and 14) compared with a normal tracing $(C)$ in a control subject.

and creatinine clearance was less good $(r=0.54$, P < 0.01) (Figure 2). One patient (no. 4) was studied on two occasions. After her initial investigation (4a in Table II), a partial hepatectomy was performed. However, it was not possible to remove the entire tumour. Thirteen months later she was re-studied when the liver was again extensively infiltrated by tumour. Renal perfusion was again abnormal and the glomerular filtration rate reduced (4b). There was no obvious correlation between the type of tumour or tests of liver function and renal perfusion or creatinine clearance.

Variability between successive curves in individual patients was often marked (Table II). Gross irregularity of the washout curve was present in four of the 37 tracings in the 14 patients and these are not shown in Table I. Slight irregularity was present in a further three curves. Variability and irregularity of ${ }^{133}$ Xenon washout has been described in cirrhotic patients and attributed to renal haemodynamic instability (Epstein et al, 1970). Instability of this sort has not been encountered in renal ischaemia from other causes, and it is thought to indicate active renal vasoconstriction in cirrhotic subjects with functional renal failure (Epstein et al, 1970). The pattern and degree of variability and irregularity of ${ }^{133}$ Xenon washout in the patients with hepatic malignancy was similar to that seen in a group of cirrhotic subjects with normal blood urea levels (Kew et al, 1971).

\section{Discussion}

Although functional renal failure most frequently complicates cirrhosis of the liver, it has also been described in patients with severe acute hepatitis 
(Summerskill, 1960) and hepatic tumours (Vesin et al, 1965). The cause of the renal circulatory changes thought to be responsible for renal dysfunction in these circumstances is not known, and a consideration of the factors common to these three conditions may shed some light on the understanding of the mechanism or mechanisms involved.

Functional renal failure usually develops in cirrhotic patients in the advanced stages of the disease when refractory ascites is present and liver function poor (Papper et al, 1959; Baldus et al, 1964a; Shear et al, 1965). Little is known about the cases of acute hepatitis in which this complication occurred except that they were severe and that renal failure developed in the terminal stages of the illness (Summerskill, 1960); it is, however, very likely that hepatic failure was present. Because functional renal failure usually occurs against a background of hepatic failure, and because an increased renal vascular resistance (Baldus et al, 1964c; Tristani and Cohn, 1967) and decreased renal perfusion (Baldus et al, 1964b; Schroeder et al, 1967; Tristani and Cohn, 1967; Epstein et al, 1970) have been demonstrated in these patients, it was suggested that some vasoactive substance may be released from or not metabolized by the failing liver (Summerskill, 1966; Barnardo, Summerskill, Strong, and Baldus, 1970; Baldus, 1970). Of the five patients with hepatic malignancy and functional renal failure reported by Vesin and his coworkers (1965), only one was jaundiced, and liver function was well maintained in our patients. It therefore seems unlikely that the renal circulatory changes in these patients are due to liver failure. However, some as yet unidentified substance capable of increasing renal vascular tone may be released as a result of malignant infiltration of the liver. The fact that these changes have occurred with a variety of both primary and secondary tumours favours an origin of such a substance in the invaded liver rather than the tumour tissue itself.

Alternatively, it has been postulated that the renal haemodynamic changes in liver failure may be due to the accumulation of false neurochemical transmitters (Fischer and Baldessarini, 1971). The precursors of these substances, such as phenylalanine, tyrosine and their amines, are produced in the bowel and are normally catabolized in the liver. When hepatic function is impaired or blood is shunted past the liver these precursors may flood the nervous system, be locally $\beta$-hydroxylated and replace normal transmitters, resulting in a loss of arteriolar tone and shunting of blood away from the kidney to the peripheral circulation. This hypothesis does not, however, explain the increased renal vascular resistance found in these patients (Baldus $t$ t al, 1964c; Tristani and Cohn, 1967) or why there is a redistribution of intrarenal blood flow away from the cortex (Baldus et al, 1964c; Shear et al, 1965; Schroder et al, 1967; Tristani and Cohn, 1967; Kew et al, 1971a). Renal haemodynamic changes have also been described in patients with non-cirrhotic portal hypertension (Kew et al, 1971b), which suggests that some endogenous substance capable of increasing renal vascular resistance and normally metabolized by the liver may bypass the latter in portal-systemic collateral channels. Such a substance, whether released from or shunted past the liver, would have to exert a differential effect on the renal vessels since arteriolar tone elsewhere in the circulation is normal or reduced (Tristani and Cohn, 1967; Murray, Dawson, and Sherlock, 1958). Attempts to identify endogenous vasoactive substances have thus far been unsuccessful (Barnardo et al, 1970).

Another possible explanation for these changes is that they may be caused by an increase in renal sympathetic tone. The rich adrenergic and cholinergic innervation of the renal vessels and their responsiveness to neurogenic stimulation suggests that the autonomic nervous system may play an important role in regulating renal and intrarenal blood flow (Barger and Herd, 1971). There is also some experimental support for an association between the hepatic arterial (Hori, Austen, and McDermott, 1966) and portal venous circulations (Onnis et al, 1962) and renal perfusion, mediated via the autonomic nervous system. The renal failure reported by Vesin et al (1965) and disturbances in renal perfusion and function found by ourselves in patients with malignant infiltration of the liver might be explained on the basis of interference with normal portal venous drainage or hepatic arterial circulation. This may also explain their presence in patients with well compensated cirrhosis (Epstein et al, 1970; Kew et al, 1971a) and non-cirrhotic portal hypertension (Kew et al, 1971b). Attempts at improving renal perfusion by sympathetic blockade have, however, produced conflicting results. Baldus (1970) was able to increase renal blood flow with dibenzyline if the systemic hypotension caused by this drug was prevented by expansion of plasma volume, but Epstein et al (1970) were unable significantly to alter renal haemodynamics by infusing phentolamine.

The presence of hepatic tumours may cause a marked increase in total hepatic blood flow (Wartnaby, Bouchier, Pope, and Sherlock, 1963), blood being shunted through the tumour. It is possible that, by its effect on systemic haemodynamics, this may alter renal blood flow. However, other forms of abnormal arteriovenous communication might then be expected to produce a similar effect and functional renal failure has not been reported in these condi- 
tions. Moreover, hepatic blood flow is reduced in patients with cirrhosis of the liver (Bradley, Ingelfinger, Groff, and Bradley, 1948; Redeker, Geller, and Reynolds, 1958).

There are thus several possible mechanisms whereby liver disease may produce renal circulatory and functional changes. The fact that oliguric renal failure has only rarely been described in patients with malignant disease of the liver and has not been reported in non-cirrhotic portal hypertension, while it is not uncommon in patients with decompensated cirrhosis of the liver, suggests that the causative factors may be additive and that more than one factor is necessary before renal and cortical perfusion reaches a critical level at which azotaemia and oliguria occur.

M.C.K. is in receipt of a Wellcome research grant and R.R.V. a grant from the Medical College of Wisconsin. Financial support for the study was provided by the Ingram Trust. We are grateful to Mr D. J. Sampson and our colleagues in the Department of Radiology for their assistance.

\section{References}

Andersen, A. M., and Ladefoged, J. (1965). Relationship between hematocrit and solubility of ${ }^{135} \mathrm{Xe}$ in blood. J. pharm. Sci., 54, 1684-1685.

Baldus, W. P. (1970). Etiology and management of renal failure in cirrhosis and portal hypertension. Ann. N.Y. Acad. Sci., 170, 267-276.

Baldus, W. P., Feichter, R. N., and Summerskill, W. H. J. (1964a). The kidney in cirrhosis. I. Clinical and biochemical features of azot mia in hepatic failure. Ann. intern. Med., 60, 353-365.

Baldus, W. P., Feichter, R. N., Summerskill, W. H. J., Hunt, J. C., and Wakim, K. G. (1964b). The kidney in cirrhosis. II. Disorders of renal function. Ann. intern. Med., 60, 366-377.

Baldus, W. P., Summerskill, W. H. J., Hunt, J. C., and Maher, F. T. (1964). Renal circulation in cirrhosis: observations based on catheterization of the renal vein. J. clin. Invest., 43, 1090-1097.

Barger, A. C., and Herd, J. A. (1971). The renal circulation. New Engl. J. Med., 284, 482-490.

Barnardo, D. E., Summerskill, W. H. J., Strong, C. G., and Baldus, W. P. (1970). Renal function, renin activity and endogenous vasoactive substances in cirrhosis. Digest. Dis., 15, 419-425.

Bradley, S. E., Ingelfinger, F. J., Groff, A. E., and Bradley, G. P. (1948). Estimated hepatic blood flow and hepatic venous oxygen content in cirrhosis of the liver. Proc. Soc. exp. Biol. (N.Y.), 67, 206-207.

Dobson, E. L., and Warner, G. F. (1957). Measurement of regional sodium turnover rates and their application to the estimation of regional blood flow. Amer. J. Physiol., 189, 269-276.

Epstein, M., Berk, D. P., Hollenberg, N. K., Adams, D. F., Chalmers, T. C., Abrams, H. L., and Merrill, J. P. (1970). Renal failure in the patient with cirrhosis: The role of active vasoconstriction. Amer. J. Med., 49, 175-185.
Fischer, J. E., and Baldessarini, R. J. (1971). False neurotransmitters and hepatic failure. Lancet, 2, 75-80.

Hori, M., Austen, W. G., and McDermott, W. V., Jr. (1966). Role of hepatic arterial blood flow and hepatic nerves in renal circulation and function. I. Acute studies in the dog. Ann. Surg., 162, 849-862.

Ingvar, D. H., Lassen, N. A. (1962). Regional blood flow of the cerebral cortex determined by krypton. Acta physiol. scand., 54, 325-338.

Kew, M. C., Brunt, P. W., Varma, R. R., Hourigan, K. J., Williams, H. S., and Sherlock, S. (1971 a). Renal and intrarenal blood flow in cirrhosis of the liver. Lancet, 2, 504-510.

Kew, M. C., Limbrick, C. A., Varma, R. R., and Sherlock, S. (1971b). Renal and intrarenal blood flow in non-cirrhotic portal hypertension. Submitted for publication.

Ladefoged, J. (1966). Measurements of the renal blood flow in man with the ${ }^{138}$ Xenon washout technique. Scand. J. clin. Lab. Invest., 18, 299-315.

Murray, J. F., Dawson, A. M., and Sherlock, S. (1958). Circulatory changes in chronic liver disease. Amer. J. Med., 24, 358-367.

Newman, M. H., and Skinner, D. B. (1969). Comparative measurement of renal blood flow by Xenon ${ }^{133}$ clearance and electromagnetic flowmeter methods. Amer. Surg., 35, 879-885.

Onnis, M., Schumacker, H. B., Jr., and Bounous, G. (1962). Response to occlusion of the portal vein: blood pressure and renal blood flow. Arch. Surg. (Chic.), 85, 897-900.

Papper, S., Belsky, J. L., and Bleifer, K. H. (1959). Renal failure in Laennec's cirrhosis of the liver. I. Description of clinical and laboratory features. Ann. intern. Med., 51, 759-773.

Redeker, A. G., Geller, H. M., and Reynolds, T. B. (1958). Hepatic wedge pressure, blood flow, vascular resistance and oxygen consumption in cirrhosis before and after end-to-side portacaval shunt. J. clin. Invest., 37, 606-618.

Rosen, S. M., Hollenberg, N. K., Dealy, J. B., Jr., and Merrill, J. P. (1968). Measurement of the distribution of blood flow in the human kidney using the intra-arterial injection of ${ }^{133}$ Xenon. Relationship to function in the normal and transplanted kidney. Clin. Sci., 34, 287-302.

Schroeder, E. T., Shear, L., Sancetta, S. M., and Gabuzda, G. J. (1967). Renal failure in patients with cirrhosis of the liver. III. Evaluation of intrarenal blood flow by para-aminohippurate extraction and response to angiotensin. Amer. J. Med., 43, 887-896.

Shear, L., Kleinerman, J., and Gabuzda, G. J. (1965). Renal failure in patients with cirrhosis of the liver. I. Clinical and pathologic characteristics. Amer. J. Med., 39, 184-198.

Summerskill, W. H. J. (1960). Pathogenesis and treatment of disorders of water and electrolyte metabolism in hepatic disease. Proc. Mayo Clin., 35, 89-97.

Summerskill, W. H. J. (1966). Hepatic failure and the kidney. Gastroenterology, 51, 94-107.

Ter-Pogossian, M. M., Koehler, P. R., and Potchen, E. J. (1968). In vivo autoradiography of ${ }^{133}$ Xenon distribution in the cystic human kidney. Radiology, 91, 358-362.

Thorburn, G. D., Kopald, H. H., Herd, J. A., Hollenberg, M., O'Morchoe, C. C. C., and Barger, A. C. (1963). Intrarenal distribution of nutrient blood flow determined with Krypton ${ }^{85}$ in the unanesthetized dog. Circulat. Res., 13, 290-307.

Tristani, F. E., Cohn, J. N. (1967). Systemic and renal hemodynamics in oliguric hepatic failure: effect of volume expansion. J. clin. Invest., 46, 1894-1906.

Vesin, P., Roberti, A., and Viguié, R. (1965). Défaillance rénale fonctionelle terminale chez des malades atteints de cancer du foie, primitif ou secondaire. Sem. Hob. Paris, 41, 1216-1220.

Wartnaby, K. M., Bouchier, I. A. D., Pope, C. E., and Sherlock, S. (1963). Hepatic blood flow in patients with tumors of the liver. Gastroenterology, 44, 733-739.

Zilversmit, D. B. (1960). The design and analysis of isotope experiments. Amer. J. Med., 29, 832-848. 